\title{
DIAGNOSTICO Y TRATAMIENTO DE ENFERMEDADES INFECCIOSAS EN EL NINYO *
}

\author{
Frof. JULIO MENEGHELLO y Drs. OSCAR UNDURRAGA, CARMEN AGUILO, \\ HAYDEE SEPULVEDA, ALEJANDRO MANTEROLA y ROMILDA BANFI \\ Hospical "Manue] Arriarán".
}

\section{(Continuación)}

\section{Laringitis obstructiva}

La obstrucción laringea es un síndrome relativamente frecuente en la infancia, especialmente en el niño menor y que plantea importantes problemas diagnósticos y de tratamiento. Sus causas son variadas (infecciones, tumores, aspiración de cuerpos extraños o cáusticos, parálisis laríngea), pero destacan en la práctica pediatrica, las relacionadas con el cuadro de las Laringitis Obstructivas. El comentario de esta exposición se basa en la experiencia recogida en nuestro Servicio, desde 1947 a 1954, sobre 279 enfermos con laringitis obstructiva que han sido estudiados a través de una planificación previa. Setenta y nueve fueron catalogados como diftéricas, 94 como sarampionosas y 149 como infecciones agudas (mierobiana, a virus).

\section{Concepto, etiología y frecuencia}

Es una afección laringea infecciosa, que se acompaña de manifestaciones clinicas de obstrucción respiratoria alta, condicionadas por lesiones generalmente inflamatorias.

En nuestra experiencia el mayor número de casos correspondió a laringitis "microbianas" (infecciosas agudas de Chevalier Jackson) 46,2\%; el resto de los casos se determina fundamentalmente por la difteria $(24,5 \%)$ y el sarampión $(\mathbf{7 9 , 3}$ por ciento).

La laringitis obstructiva constituye el motivo de ingreso de aproximadamente el $10 \%$ de los enfermos en nuestro Servicio de Enfermedades Infecciosas. Existe una mayor incidencia en las estaciones frías del año, susceptibles de influenciarse por la aparición de brotes epidémicos de las enfermedades causales. Es una afección que predomina manifiestamente en el lactante mayor y preescolar.

- Fxtracto de clases dictadas en Curso de Perfeccionamiento de Pediatria, 1954.

\section{Necesidad de un diagnóstico oportumo}

a) Antecedentes: Enfermedad infecciosa específica, catarro previo de las vías respiratorias, alergia familiar o personal, crisis anteriores, antecedentes de cuerpo extraño en las vías aéreas. Forma de comienzo, que en nuestra experiencia demostró ser algo más lento en las formas diftéricas $(63,3 \%)$ que en los otros tipos etiológicos (alrededor del $40 \%$ ).

b) Manifestaciones clínicas de obstrucción crupal, disfonía, disnea, tiraje, cornaje. Estas alteraciones pueden conducir por anoxia a la cianosis, inconsciencia y muerte.

c) Estudio endoscópico: debe realizarse por rino, laringo y broncoscopía. Puede comprobarse en la laringe, congestión $(80,4 \%$ y $62 \%$ de las Jaringitis sarampionosas y laringitis microbianas), edema alrededor del $50 \%$ en las formas no diftéricas) y exudado, que es la lesión fundamental en la laringitis diftérica, de carácter membranoso (localizado en la glotis en el $41,6 \%)$. En las laringitis sarampionosas y laringitis microbianas el exudado estuvo presente en el $56,5 \%$ y $31,3 \%$, respectivamente; en estos casos el exudado de tipo puriforme puede plantear difíciles problemas diagnósticos.

d) Estudio bacteriológico de las secreciones nasal, faringea y laríngea. En nuestra experiencia este estudio demostró que el $61,7 \%$ de las laringitis diftéricas fué primitiva. En las otras formas hubo predominio de Stafilococo Albus, dorado hemolítico y neumococo.

\section{Pautas de tratamiento}

a) Ambiente adecuado: humedad ( 80 por ciento) temperatura $20^{\circ}$ a $23^{\circ} \mathrm{C}$. ( $\mathrm{La}$ Cámara Croupal cumple ampliamente estos propósitos).

c) Aspiración de secreciones y nebulización con aerosol y antibióticos.

c) Intubación, de preferencia en las laringtis diftéricas (aproximadamente se realizó en el 50\% de nuestros casos), y de acuerdo a los hallazgos endoscópicos en las laringitis sarampionosas y microbianas 
(20\% de nuestros pacientes). No debe mantenerse más de 96 horas.

d) Traqueotomia, de elección en las difterias descendentes o en la localización subglótica de cualquier tipo de laringitis. No es prudente mantener la cánula más de 10 días.

e) Antitoxina djftérica (aproximadamente 30.000 U.), que también debe indicarse en duda diagnóstica.

f) Antibióticos: penicilina-procaína $(300,000 \mathrm{U}$. cada 12 horas $)$, a veces asociada a estreptomicina 150 a $300 \mathrm{mg}$. cada 12 horas I; clorcmicetina 50 a $100 \mathrm{mg}$. por kilo). Los antibióticos se mantendrán entre 7 y 10 días.

g) Cortisona $(100$ a $200 \mathrm{mg}$. diariamente), puede tener indicación para controlar los fenomenos de edema y espasmo.

\section{Resultados}

Generalmente al término de la primera semana ha caído la temperatura y ha mejorado apreciablemente el sindrome obstructivo.

Mortalidad global: $8,9 \%$. La mortalidad es manifiestamente más alta en las formas diftéricas $(21,5 ; r)$.

Complicaciones: Ia más importante, la bronconeumonía (alrededor del $15 \%$ ). Son escasas las secuelas laríngeas de orden instrumental o secundarias a la misma laringitis, que condicionan paresias o estrecheces.

VI. Diagnóstico clínico, diferencial y tratamiento de la poliomielitis en su fase aguda

El reconocimients de la enfermedad en sus primeras etapas permite establecer la única medida que puede señalarse como de positivos efectos sobre el curso de la afección: El reposo, pero también es fundamental saber cuando las parálisis ponen en peligro la vida del enfermo (compromiso bulbar o parálisis de los músculos respiratorios) y recordar los puntos fundamentales en que se basa el tratamiento actual de las parálisis y el alivio del dolor. El reconocimiento oportuno de cuadros paralíticos y de curso diferente al de la poliomielitis obliga también a puntualizar algunos cuadros de diagnóstico diferencial interesante.

\section{Curso elínico de la poliomielitis}

Se pueden presentar las siguientes fases o etapas sucesivas: a) Periodo de incubación variable, alrededor de 12 dias se- gún últimas investigaciones $\mathrm{y}$ durante el cual el futuro enfermo elimina el virus por las deposiciones y coadyuva a la diseminación. b) Periodo febril inicial, en promedio de 2 días de duración y caracterizado por fiebre, malestar, cefalea moderada, faringitis, vómitos, náuseas, anorexia. No hay signos de irritación meníngea $y$ el L.C.R. es normal. Este primer episodio se presentaría según autores en no más de un tercio de los pacientes. La enfermedad puede quedar reducida sólo a esta fase (poliomielitis abortiva). c) Una interfase de 3 a 7 dias durante la cual el paciente parecía haber mejorado. d) Nueva alza febril, ahora con fiebre más alta, anorexia, cafalea, irritabilidad, somnolencia (conservando siempre una facies de alerta) y dolor de garganta sin enrojecimiento, constipación. El niño trata de no moverse y llora cuando lo cambian de posición. Hay rigidez de la columna, signo del trípode y caída de la cabeza hacia atrás al levantar al paciente de los hombros. Suele haber enrojecimiento y sudoración. El L.C.R. demuestra alteraciones; usualmente hay discreta albuminosis y pleocitosis linfocitaria. Al tercer o cuarto día se producen las parálisis, anticipadas a veces por mialgias, temblores y mioclonias. El dolor oculta la extensión verdadera de la parálisis, cuyas características son lo salpicado de su localización, la falta de reflejos. Se localizan principalmente en las extremidades inferiores, menos frecuentemente toman las extremidades superiores y mucho menos el tronco, el cueIIo y los músculos inervados por los pares craneales. El porcentaje de estas últimas complicaciones varía de epidemia en epidemia. La afección puede terminar sin presentarse las parálisis, quedando en la fase de compromiso meningeo (forma preparalítica) y en general se estima que no aparecen parálisis después de 6 a 8 días de iniciada la segunda fase febril; en la forma preparalítica dentro de este plazo el curso se hace afebril. e) El enfermo entra en convalecencia al caer la fiebre definitivamente y termina la fase aguda cuando cesan los espasmos dolorosos, inclusive el de la columna dorsal.

Junto con los sintomas paraliticos de las extremidades y a aveces aisladamente suelen comprometerse los pares craneales. En general se denomina esta forma como poliomielitis bulbar. Entre estas formas debe citarse primordialmente aquella que compromete el vago ( $\mathrm{X}$ par), cuyos file- 
tes motores dan inervación a la musculatura de la deglución y formación. Su compromiso se evidencia por la falla en estas funciones, con acumulación de secreciones en el rinofarinx que entraban el pasaje del aire. $\mathrm{El}$ mal tratamiento de esta forma puede conducir a una hipoxia larvada $y$ creciente que se manifiesta por ansiedad, desasosiego, temor, confusión mental, letargia, somnolencia y hasta llegar al coma. Muchos de estos casos son tomados como poliomielitis de forma encefálica, por la participación de las funciones superiores. Existen todos los síntomas atribuíbles a la hipoxia ya mencionados e hipertensión arterial frecuente. Uno de los últimos signos en aparecer $y$ que nunca debe esperarse para el tratamiento es la cianosis. Puede también dañarse el centro circulatorio y sus síntomas son los de una insuficiencia cardiovascular aguda, con todos los signos del shock. El compromiso aislado de otros pares craneales, especialmente el facial, no requieren especial comentario por su ustual curso hacia la mejoría espontánea.

Las parálisis de los músculos respiratorios por la lesión medular alta son frecuentes cuando se comprometen los músculos de los hombros. Se caracterizan por la respiración superficial, el lenguaje escaso y entrecortado, el aleteo nasal y por las alteraciones encontradas a la inspección y palpación del tórax. Cuando se to man los intercostales la respiración es exclusivamente abdominal y el enfermo se angustia al presionarle durante un momento el abdomen. Cuando falla el diafragma la respiración es intercostal y el paciente no tolera la compresión del tórax. Al paralizarse un lado del diafragma la respiración abdominal tiene una ca. racterística asimetría. La insuficiencia de la oxigenación intrapulmonar tiene los mismos signos clínicos de alarma ya mencionados en la parálisis bulbar.

La forma bulbar y la respiratoria espinal suelen combinarse.

\section{Diagnóstico diferencial}

Puede plantearse en las diversas fases de la afección. En la elevación térmica inicial el diagnóstico puede sospecharse sólo con el antecedente de casos típicos próximos al paciente. En la fase meníngea puede plantearse la posibilidad de una meningitis purulenta, (es fundamental la punción lumbar para dilucidar rápidamente el origen de un cuadro meníngeo), de una meningitis a líquido claro (puede ser útil el resultado del examen del L.C.R. y la presencia de rigidez de la nuca), de una meningoencefalitis de cualquier etiología (en estos casos generalmente domina la obnubilación sensorial y no existe la facies de alerta y temor a ser movilizado del poliomielítico). El examen cuidadoso del paciente y la anamnesis pondrán a cubierto de una reacción meningea secundaria a un cuadro infeccioso bien determinado (neumonía, amigdalitis, enterocolitis, etc.). En estos casos lo común es que el L.C.R. no demuestre alteraciones al examen químico celular.

En el niño con parálisis debe eliminarse la posibilidad de un traumatismo, de una herida, de un proceso inflamatorio óseo, articular o muscular. Un buen examen orientará el diagnóstico debidamente. Establecido el origen neurológico de la parálisis pueden presentarse dificultades para el diagnóstico con la polirradículoneuritis de Quillain Barré, enfermedad de curso general benigno en el sentido que pasada la fase aguda (eventualmente mortal por compromiso respiratorio y bulbar) la parálisis se recupera. En este cuadro las parálisis son simétricas, de predominio proximal (hombro y muslo), hay alteraciones de la sensibilidad y una marcada disociación albúminocitológica en el L.C.R. Otros diagnósticos que hemos tenido oportunidad de plantear son: corea paralítico (debe examinarse con detención la actividad de los dedos de los pies y manos); de un méduloblastoma del vermis cerebeloso, con compromiso motriz, sensitivo $\mathrm{y}$ del control esfinteriano); de diversas mielopatías agudas( por ejempio, la mielitis necrotizante aguda, cuyas manifestaciones medulares son también extensas y no limitadas a las astas anteriores como en la poliomielitis). Han presentado dificultades la adinamia marcada de algunas enfermedades infecciosas, en especial de la tifoidea: primero la parálisis del velo, a continuación de la acomodación y en las extremidades o en otra localización más restaringida, incluso dando manifestaciones de parálisis bulbar, con muerte en dos de nuestros pacientes.

Los accidentes vasculares agudos intracraneales dan parálisis brúscamente en forma de hemiplegias, con manifestaciones de lesión central, aunque en una primera etapa puedan dominar la hipotonía y la arreflexia. Los procesos expansivos 
intracraneales dan lugar también a parálisis de origen central.

$\mathrm{La}$ forma de poliomielitis bulbar puede confundirse inicialmente con una rabia, como en un caso de nuestra experiencia pero en la etapa inicial de esta afección domina la disfunción faríngea y no la parálisis. Otra afección confundible es el absceso retrofaríngeo, por cuanto el edema inflamatorio puede determinar la paresia muscular vecina. Las encefalitis de tipo Jocalizado (mesencefalitis) pueden evolucionar con signos bulbares, pero la historia señala generalmente una iniciación lenta y progresiva, usualmente con fiebre baja. De igual modo evolucionan los tumores del tallo cerebral con lesiones progresivas de los núcleos del puente y bulbo. Hemos mencionado el sindrome bulbar postdiftérico.

\section{Tratamiento}

Una vez iniciados los síntomas mencionados en las diversas fases de la afección no es posible determinar el cambio de la evolución con alguna medida terapéutica. Solamente se debe insistir en el reposo lo más completo posible, dado que ciertos autores han creido demostrar que en esta forma las páralisis serían menos severas. Durante el período preparalítico serian particularmente inoportunos los largos viajes y los esfuerzos en general. No se ha demostrado el beneficio a esta altura de transfusiones y otras medidas.

Aparecidas las parálisis es fundamental aliviar al paciente con una buena asistencia de enfermería: el paciente debe estar acostado con comodidad, las extremidades en posición de reposo, manteniendo la alineación del cuerpo y esta postura de reposo mediante almohadillas de arena y rollos de sábanas. Los pies deben estar en ángulo recto y el talón no debe apoyar en el colchón (cama dura y cubos de madera entre el colchón y un tablero de apoyo). Debe cambiarse de posición con frecuencia para evitar la fatiga, pero manteniendo la alineación corporal constantemente. Las manipulaciones deben reducirse al mínimo durante el período de dolor, y los exámenes musculares deberán posponerse hasta que se alivie el dolor. Las compresas calientes colocadas cuatro a seis veces al día en las extremidades paralizadas y con dolor contribuyen eficazmente a aliviar el enfermo al paso que aumenta la circulación muscular y disminuyen las complicaciones musculares (trom- boflebitis). La excitación debe calmarse con barbitúricos. La constipacion se combate mejor con supositorios de glicerina o pequenos enemas y la retencion urinaria con sondeo. La dieta sera completa pero liviana; debe evitarse la hipoalımencación a menos que se presenten trastornos nutritivos aguaos intercurrentes. La escaras pueden prevenirse con el aseo constante de la piel y los eambios de pasicion oportunos. Una vez cesado el dolor' se mnciaran los movimientos pasivos, los masajes, los ejercicios activos y la correccuon de las posiciones viciosas. En la 1orma bulbar, con compromiso del vago, se indicara aspiración continua de las secreclones, drenaje postural ('Irendelenburg) e hidratacion paraenteral. Én caso necesario, oxugenorexapia. No es conveniente usar la sunda gascrica para la alımentación de estos enfermos en la tase aguda por el peligro de la aspiracion de contenido gásirico. La presencia de los signos de hipoxia cerebral de alarma indica en estos casos que el tratamiento no se está hacrendo en forma adecuada y es preferible, según muchos autores, proceder a una traquetomía precoz. Tambien es aconsejable esta intervención cuando eualquier cırcunstancia impide la assstencia adecuada del paciente bulbar.

Las parálisis de los músculos respiratorios requieren en casos incipientes que se tranqullice, se dé confianza y se eviten los esfuerzos al paciente; puede ser buena práctica ordenar verbaimente la respiración. La dificultad para responder con voz entera y la presencia de contracciones peribucales, unido a los síntomas de hopoxia indica la necesidad de colocar al paciente en el respirador. Este aparato debe usarse precozmente, con una presión negativa aproximadamente de $15 \mathrm{cms}$. de agua y con un ritmo de 32 movimientos por minuto para los niños menores de 2 anos y de 20 para los mayores de 10.

Es preferible ventilar en exceso en los primeros días que dejar en hipoventilación y, además, se tratará de evitar el acostumbramiento, deteniendo el pulmotor por algunos segundos y en forma cada vez mas prolongada de acuerdo con la reacción del paciente, en cuanto el período crítico haya pasado. Es indispensable que junto con el respirador se empleen el resto de las medidas ya señaladas, debiendo tenerse presente que es indispensable mantener las vías respiratorias limpias y permeables cuando se usa el pulmotor. 